Dept. of Animal Behavior and Management,

Fac. of Vet. Med., Assiut University.

\title{
STUDIES ON SOME PATTERNS OF SEXUAL BEHAVIOR IN NORMAL AND STRESSED RABBITS
}

(With 3 Tables)

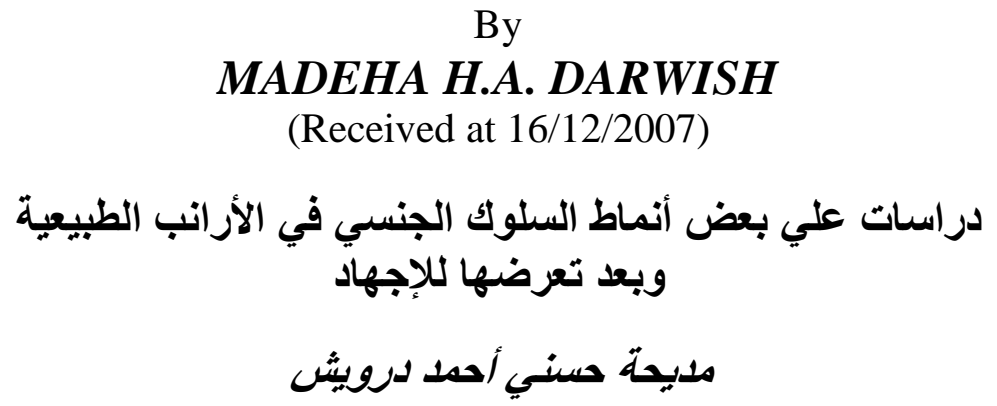

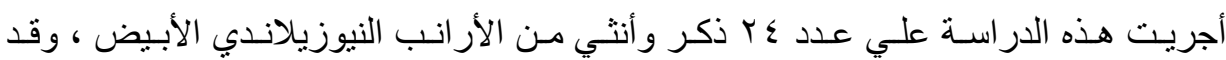

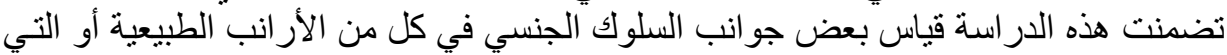

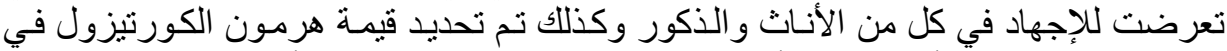

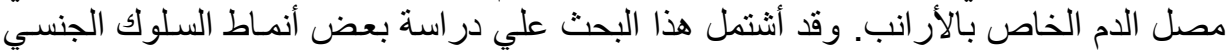

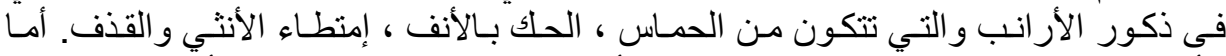

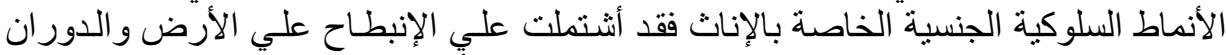

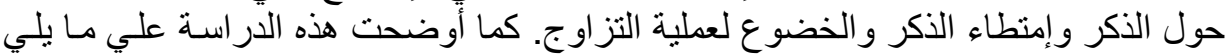

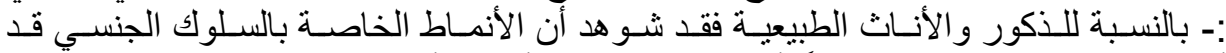

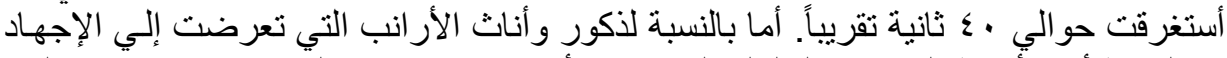

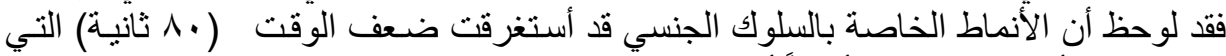

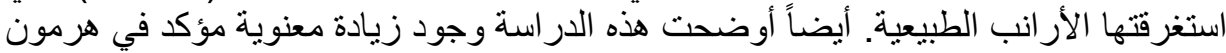

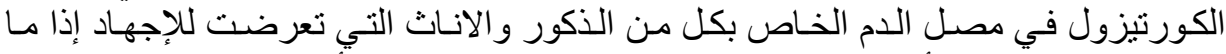

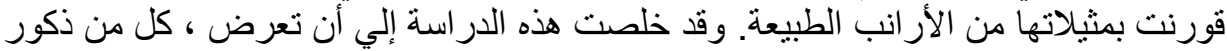

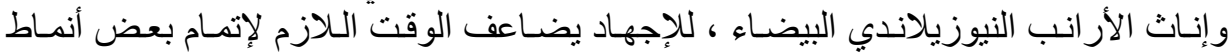
السلوك الجنسي الخاصة بها.

\section{SUMMARY}

Twelve males and females $(\mathrm{n}=24)$ white New Zealand rabbits were used to evaluate some patterns of sexual behavior in normal and after exposure to emotional stress. The main aspects of sexual behavior which were observed in male rabbit were inactivity, nuzzling the female, mounting and ejaculation. The female rabbits showed different sexual behavior such as flattening and circling, mounting the male and lordosis and submission to mating. After introduction of a female rabbit into the 
male's cage for 2 minutes, the duration of the behaviors in both sexes was recorded in seconds using stopwatch. The results showed that, control male rabbits remained inactive for a significantly shorter time as compared with stressed male rabbits. Also the results indicated that control males performed nuzzling and mounting the females for shorter time than those counted for the stressed ones. Further more control female rabbits were alternately flattened and circled inside the cage for a significantly lesser time as compared to stressed females where they flattened longer in a corner of the cage. In addition comparison of these behavioral events between control and stressed animals showed that in control female rabbits, mating occurred within 40 seconds after introduction into the male's cage; however stressed female rabbits spent about double the time needed for the control group. The sexual performance of stressed male rabbits showed expression of sexual aggressiveness such as enuresis, grasping and kicking toward the female rabbits inside the cage. The studies of steroid assays revealed that, the mean cortisol concentrations of both stressed male and female rabbits were significantly higher than those measured in control ones. Moreover, the rises in the serum concentrations of cortisol levels in stressed female rabbits) were significantly higher compared to control ones.

Key words:

\section{INTRODUCTION}

Sexual behavior is a very complex phenomenon with involvement of many components, including the participation of the endocrine glands as well as central and peripheral nervous system (Crews, 1993). Female rabbit ovulate in response to copulation. Moret (1980) observed that, in non-pregnant non-pseudo pregnant doe rabbits, an alteration of periods of receptivity occur during which females submitted to matting, followed by periods of non-receptivity. Cycles of receptivity of 6 or 7 days have been described in wild and domestic female rabbits (Myers and Poole, 1962).

Improvement and optimization of the methods used to detect reproductive disorders in experimental animals are among the main challenges facing researchers in this field. Sexual behavior can be studied by giving arbitrary values to different behavioral components. In male rabbits sexual behavior can be scored if values are given to different behavioral patterns observed during mating; such as: inactivity; 
courting and nuzzling; mounting; time between mounting and ejaculation; and the percentage of animals that ejaculate (Hokao et al., 1993 and Nelson, 1995).

There is evidence that the display of sexual behavior and mating can be affected and/or modified by different factors including environmental changes and the effect of drugs such as alcohol and opioid agonists and antagonists (Hetta, 1977 and McIntosh et al., 1980). There is increasing evidence that variations in prenatal environment can influence the reproductive capability of the newborn rats (Maccari et al., 2003). For many years, the stress response induced by physical or emotional challenges has been recognized as a profound disruptive factor in reproductive function in both males and females (Velazquez, et al., 1993 and Ward et al., 2002).

Based on the above consideration, different types of stressful events may sometimes produce qualitatively different patterns of effects on both behavioral patterns and physiology in different animal models (Blanchard et al., 2001). The present study was designed to examine different components of sexual behavioral patterns in control adult male and female rabbits and after exposing them to an emotional stress just before mating and in relation to the circulating cortisol concentrations.

\section{MATERIALS and METHODS}

\section{Animals:}

Twelve healthy male and female $(n=24)$ New Zealand white rabbits between 8 and 12 months of age, their body weight ranged from 2.25 to $3.2 \mathrm{~kg}$ were used. They were selected at random from Faculty of Agriculture Farm, Assiut University. They were housed individually in galvanized cages $(90 \mathrm{~cm} \times 60 \mathrm{~cm} \times 40 \mathrm{~cm})$. Animals were reared in sufficiently ventilated house with 16-hours light and 8-hours dark and 25 Lux of light intensity. Cage and pens were achieved by automatic clean drinking watering system; the hopper was fitted to the outside of the cage, with the trough projecting into the cage. The nest box was attached on the outside of the hutch. Constant hygiene and routine maintenance of cages and equipments were essential and adopted. Prophylactic measures against rabbit hemorrhagic septicemia using the oil-adjuvant polyvalent rabbit pasteurellosis vaccine as well as treatment and control of both internal and external parasites were adopted. Temperature was ranged between22-24C; water and food were provided ad libitum. Rabbits were fed on formulated pellet ration, (according to El-Raffa, 1994). 
(Commercial rabbit pellets). All observed events were recorded using digital stop-watch. The rabbits were divided into two groups; a) Control group $(n=12)$ of randomly selected six males and females were not manipulated (not exposed to stress) during the experiment, and b) Stressed group $(n=12)$ of randomly selected six males and females were exposed to emotional stress before starting the sex behavioral tests.

\section{Stress exposure:}

The stressed group $(n=12)$ of both male and female rabbits were exposed to an air-puff for 5 min by using a commercial hair-dryer (air at room temperature) as an emotional stress (Darwish,1998). Exposure to the emotional stress was applied through the cage-top, just 15 min before applying the behavioral testing procedures. The control animals (stressfree) were left undisturbed in their cages during this time.

\section{Behavioral Testing Procedures:}

In the present experiment, the male rabbit was placed in an observation cage (thick wire mesh, $100 \times 50$ X $40 \mathrm{~cm}$ high) before that a receptive female was introduced. The female rabbit was then introduced into the male's cage for $2 \mathrm{~min}$. Durations of the different aspects of sexual behavior observed in both male and the female rabbits were determined using a stopwatch. For the male, the following behavioral parameters were recorded: inactivity, courting and nuzzling the female as well as mounting and ejaculation. Moreover, in the female rabbits, the following behavioral events were determined: flattening to the floor in a corner of the cage, circling around the cage, mounting the male, lordosis and submission to mating, and vocalization. If the female submitted to mating, she was removed and not presented to other males during the same day. Before testing, the colour of the vulva was noted. Female rabbits were shown to exhibit moist red purple vulva. The experiments were done using both control males and females $(n=12)$ as well as stressed males and stressed females. The whole experiments were repeated three times and the values were expressed as mean \pm s.e.m.

\section{Steroid assays:}

After behavioral testing, blood samples $(5 \mathrm{ml})$ were collected to determine the profile of serum cortisol in response to stress. The collected blood samples from each individual animal was collected from margin ear vein in centrifuge tube and then centrifuged at 3000 r.p.m. for 30 minutes. Plasma was stored at $-20 \mathrm{C}$ until analyses as recommended by Suckow and Douglas (1997). Serum levels of cortisol were estimated using Immulite Cortisol Kits with Immulite analyzer (DPC, ver.411).

\section{Statistical analysis}


Statistical analysis was performed by using SPSS version 11.01 licensed to North Dakota State University. The data was presented as means \pm s.e.m.values. One-way analysis of variance (ANOVA) used to compare between all samples present as $\mathrm{P} \leq 0.05$.Mann-Whitney UWilcoxon Rank Sum W Test was also used to compare between any two samples.

\section{RESULTS}

\section{Sexual behavioral aspects of the male rabbits (Table 1):}

The results showed that, in the presence of receptive (nonpregnant non-pseudo-pregnant) female rabbit, the control male rabbits remained inactive for a significantly $(\mathrm{p} \leq 0.05)$ shorter time $(9 \pm 1 \mathrm{sec})$ as compared with stressed male rabbits $(19 \pm 2 \mathrm{sec})$. Also, control males performed nuzzling $(21 \pm 2 \mathrm{sec})$ and mounting $(10 \pm 2 \mathrm{sec})$ of the females are significantly $(\mathrm{p} \leq 0.05)$ shorter time than those counted for the stressed ones ( $41 \pm 3 \mathrm{sec}$ and $20 \pm 3 \mathrm{sec}$, respectively). The total time of these aspects of sexual behavior from the introduction of the receptive female into the cage of control male rabbits in the presence of receptive does was about $50 \%$ shorter $(40 \pm 2 \mathrm{sec})$ compared with stressed males $(80 \pm 4 \mathrm{sec})$.

The sexual performance of stressed male rabbits showed expression of frequently observed certain sexual aggression such as enuresis, grasping and kicking of the female rabbits inside the cage.

\section{Sexual behavioral aspects of the female rabbits (Table 2):}

The present study showed that the control female rabbits were alternately flattened and circled inside the cage for significantly ( $\mathrm{p} \leq$ $0.05)$ lesser time $(20 \pm 2 \mathrm{sec})$ as compared to stressed females where they flattened longer $(37 \pm 4 \mathrm{sec})$ in a corner of the cage. In addition, comparison of the behavioral events of both control and stressed animals showed that in control female rabbits, mating [occurred within 40 seconds after introduction into the male cage, while the stressed female rabbits spent double the time $(80 \mathrm{sec})$ needed for the control animals. In the present experiments, all female rabbits during mating showed vocalization in both a sporadic or continuous manner, and no significant differences were observed in the occurrence of this behavioral sign. Females with reddish or purplish valva remained unchanged after stress, and no relationship between stress and colour of the valva was observed.

\section{Serum Cortisol Concentrations (Table 3):}


The present experiment revealed that the mean cortisol concentrations of stressed male rabbits $(230.35 \pm 10.32 \mathrm{ng} / \mathrm{dl})$ were significantly $(\mathrm{p} \leq 0.05)$ higher than those measured in control ones $(177.50 \pm 8.24)$.In addition, the rises in the serum concentrations of cortisol levels $(248.70 \pm 10.51)$ in stressed female rabbits were significantly $(\mathrm{p} \leq 0.05)$ higher as compared to non-stressed does $(181.60$ $\pm 7.95)$.

Table 1: Changes in the values (in seconds) of sexual behavior in control and stressed male rabbits. Values are mean \pm s.e.m. for triplicate observations.

\begin{tabular}{|c|l|l|l|l|l|}
\hline \multicolumn{2}{|c|}{ Aspects } & Inactivity & $\begin{array}{l}\text { Courting \& } \\
\text { nuzzling }\end{array}$ & $\begin{array}{l}\text { Mounting \& } \\
\text { ejaculation }\end{array}$ & $\begin{array}{l}\text { Total \& time } \\
(\mathrm{sec})\end{array}$ \\
\hline \multirow{3}{*}{$\pi$} & $\begin{array}{l}\text { Control } \\
\mathrm{N}=6\end{array}$ & $9 \pm 1$ & $21 \pm 2$ & $10 \pm 2$ & $40 \pm 2$ \\
\cline { 2 - 6 } & $\begin{array}{l}\text { Stressed } \\
\mathrm{N}=6\end{array}$ & $19 \pm 2 *$ & $41 \pm 3 *$ & $20 \pm 3 *$ & $80 \pm 4 *$ \\
\hline
\end{tabular}

$*$ significant at $\mathrm{p} \leq 0.05$

Table 2: Changes in the values (in seconds) of sexual behavior in control and stressed female rabbits. Values are mean \pm s.e.m. for triplicate observations.

\begin{tabular}{|c|l|l|l|l|l|}
\hline \multicolumn{2}{|c|}{ Aspects } & $\begin{array}{l}\text { Flattening \& } \\
\text { circling }\end{array}$ & $\begin{array}{l}\text { Mounting } \\
\text { the male }\end{array}$ & $\begin{array}{l}\text { Lordosis \& } \\
\text { mating }\end{array}$ & Total \\
\hline \multirow{2}{*}{$\begin{array}{c}\text { Animals } \\
+\end{array}$} & $\begin{array}{l}\text { Control } \\
\mathrm{N}=6\end{array}$ & $20 \pm 2$ & $8 \pm 1$ & $10 \pm 1$ & $38 \pm 3$ \\
\cline { 2 - 5 } & $\begin{array}{l}\text { Stressed } \\
\mathrm{N}=6\end{array}$ & $37 \pm 4 *$ & $21 \pm 2 *$ & $20 \pm 2 *$ & $78 \pm 3 *$ \\
\hline
\end{tabular}

$*=$ significant at $\mathrm{p} \leq 0.05$

Table 3: Patterns of cortisol concentrations in serum in control and stressed male and female rabbits. Values are mean \pm s.e.m. for triplicate observations

\begin{tabular}{|c|c|c|}
\hline \multirow{2}{*}{ Animals } & \multicolumn{2}{|c|}{ Serum cortisol levels ( ng / dl ) } \\
\cline { 2 - 3 } & Control & Stressed \\
\hline Male & 177.50 & $230.35^{*}$ \\
& \pm 8.24 & \pm 10.32 \\
\hline Female & 181.60 & $248.70^{*}$ \\
& \pm 7.95 & \pm 10.51 \\
\hline
\end{tabular}

$*=$ significant at $\mathrm{p} \leq 0.05$

\section{DISCUSSION}


After introduction of a female rabbit into the male's cage from the control group, the male began to nuzzle her around the genital area and behind the ears or tried to mount her. In control group, males remained inactive for a very short period, then mount and ejaculation occurred within 40 seconds followed by a backward lunge of the male away from the female. Moreover, when the control females submitted to mating, it alternately flattened and circled inside the cage, then took the position of lordosis and copulation occurred rapidly with vocalization that occurred in a sporadic or continuous manner.

When the stressed females submitted to mating, she flattened longer on the floor in a corner of the cage, and then the male rabbit could nuzzle her, scratch the female's back with his forelegs; or beat her ears. The female try to run from the male and circle around the inside of the cage and tried to mount the male and then followed by mating after double the time spent in control females. Stressed female rabbits also vocalized during the test. The stressed male rabbit showed longer periods for inactivity, nuzzling and mounting with doubled time score, compared to control ones.

The results of the present study constitute the quantitative analysis of some pattern of the sexual behavior of both male and female rabbits in normal and after exposure to emotional stress. Many of the behavioral events which have been reported for wild rabbits are also observed in domestic rabbits. However, few data are available on the sexual behavior of the male rabbit. Southern (1947) and Worden \& Leahy (I962), have identified different sexual behaviors in the confined Wild rabbit: courtship chasing (sexual following, circling and jumping), tail 'flagging', enuresis, and copulatory behavior. Similar behavioral events have been observed by Heath (1972) for domestic rabbits. In our study, the males displayed 3 important behaviors, nuzzling and mounting, and remained inactive for a short time during the tests. A quantitative difference in male behavior was noted in the presence of receptive females. The domestic rabbit has been reported to use a variety of scent-marking behaviors. A territorial function for chin-marking was first described by Mykytowycz (1968) for the wild male rabbit. Heath (1972) has noted that the domestic bucks marked a variety of inanimate objects as well as the females in this manner. This particular behavior has not been observed in our study, perhaps because the tests were performed in the male's cage, i.e. in his own territory. Furthermore, the experienced males used in this study were trained to mount the females. 
When introduced into the male's cage, the female rabbit displays 2.main behaviors: flattening in the corner of the cage and/or circling away from the male. These sexual behaviors have been described by for domestic female rabbits (Heath, 1972 and Stoufflet and Caillol, 1988).

The difference between a receptive and a non-receptive female is not easy to establish in the rabbits. As for the male, a quantitative difference of behavior was observed between stressed and non-stressed male and female rabbits. In our study, mounting the male was always followed by submission to mating even in stressed animals in contrast to what has been reported by Hammond \& Marshall (1925) and agreed with those recently reported by Yaschine et al. (1967); Beyer and McDonald (1973) and Stoufflet and Caillol (1988).

It has been known for a long time that stress adversely affects reproduction by changing the endocrine status of the body (Selye, 1939). Endocrine control of reproduction is mediated principally by the hypothalamus through secretion of Gonadotropin Releasing Hormone $(\mathrm{GnRH})$. This decapeptide is responsible for Follicle Stimulating Hormone (FSH) and Luteinizing Hormone ( $\mathrm{LH})$ secretion from the anterior pituitary which in turn, act on the gonads to regulate follicular growth, ovulation, steroidogenesis and spermatogenesis. On the other hand, stressful stimuli activate the hypothalamo-pituitary-adrenal axis (e.g. through hypersecretion of corticotrophic releasing hormone (CRH) arginine vasopressin (AVP) adrenocorticotrophic hormone (ACTH) and cortisol and threaten normal homeostasis (Phogat et al., 1997). Most data suggested that after stress, CRH depresses GnRH secretion through a central site of action, at the hypothalamic level by lowering plasma LH values can block ovulation in females, and reduce testosterone; in cows (Stoebel and Moberg, 1979); in sheep (Matteri et al., 1986); in male rats (Almeida et al., 1988) and in ewe (Enert and Moberg, (1991). Moreover, a possible role of the inhibitory effect of CRH and/or ACTH on delayed sexual maturation in mice and blocked ovulation in rats has been reported by Christian, 1964 and Hagino et al., 1969.

It has been suggested that stress affects reproduction at the hypothalamic level, mediated through the opioid substances (beta endorphin, enkephalin) and catecholamine (adrenalin, nor-adrenalin) pathway in rats and monkeys (Rivier and Rivest, 1991; Norman et al., 1994; Daniela et al., 2005). Briski and Sylvester (1988) suggested that gonadal steroids play an important role in modulating acute stressinduced alterations in LH secretion; however, the nature of the stressor is also important. Based upon the previously mentioned data, it can be 
suggested that the delayed aspects of sexual behavior in both male and female rabbits after exposure to emotional stress are due to the inhibitory effect of CRH (stress released hormone) on the gonadal function and in turn on the components of sexual behavior in rabbits.

\section{REFERENCES}

Almeida, O.F.X.; NiKolarakis, K.E. and Herz, A. (1988): Evidence for the involvement of endogenous opioid peptides in the inhibition of luteinizing hormone by corticotropin-releasing factor. Endocrinology 122, 1034-1041.

Beyer, C. and McDonald, P. (1973): Hormonal control of sexual behaviour in the female rabbit. Adv Reprod Physiol. 6, 185-214.

Blanchard, R.J.; Mckittrick, C.R. and Blanchard, C. (2001): Animal models of social stress: effects on behavior and brain neurochemical systems. Physiol. Behav. 2001; 73: 261-71.

Briski, K.P. and Sylvester, P.W. (1988): Effect of specific acute stressors on luteinizing hormone release in ovariectomized and ovariectomized estrogen-treated female rats. Neuroendocrinology 47, 194-202.

Christian, J.J. (1964): Effect of chronic ACTH treatment on maturation of intact female mice. Endocrinology 74, 669-674.

Crews, D. (1993): Diversity hormone-behavior relation in reproductive behaviour. In: Beckerrr, J.B., Breedlove, S.M., Crews, D.A. (Eds.) Behavior Endocrinology. The Bradford Book. MIT press, Cambridge, MA, USA (Chapter5).

Daniela, C.C.G.; Pereira, O.C.M.; Kempins, W.G.; Florio, J.C; Moreira, E.G. and Bernardi, M.M. (2005): Sexual behavior, neroendocrine, and neurochemical aspects in male rats exposed prenatally to stress. Physiol. Behav. 84: 97-104.

Darwish, M.H.A. (1998): Steroid hormone control of maternal and emotional behavior and the endocrine response to stress in rats. $\mathrm{Ph}$. D. Thesis, Assiut University.

Ehnert, K. and Moberg, G. (1991): Disruption of estrous behaviour in ewes by dexamethasone or management related stress. Journal of Animal Science. 69, 2988-299.

El-Raffa, A.M.E. (1994): Some factors affecting economical, productive and reproductive traits in rabbits. Ph.D. Thesis, Fac. of Agric., Alexandria. Univ., Egypt. 
Hagino, N.; Watanabe, M. and Goldzieher, J.W. (1969): Inhibition by adrenocorticotrophin of gonadotrophin-induced ovulation in immature female rats. Endocrinology 84, 308-314.

Hammond, J. and Marshall, F. (1925): Reproduction in the Rabbit. Oliver \& Boyd, Edinburgh.

Heath, E. (1972): Sexual and related territorial behaviour in the laboratory rabbit (Oryctolagus cuniculus). Lab. Anim. Sci. 22, 684-691.

Hetta, J. (1977): Effects of morphine and naltrexone on sexual behavior on the male rat.Acta Pharmacol. Toxicol. 41 Suppl. 4,pp.53-59.

Hokao, R.; Saito, T. and Takahashi, K. (1993): Comparisson of sexual behavior patterns in small laboratory animals. Exp. Anim. 42, 451-455.

Maccari, S.; Darnaudery, M.; Morley-Fletcher, S.; Zuena, A.R.; Cinque, $C$. and Van Reeth, O. (2003): Prenatal stress and long-term consequences: implications of glucocorticoid hormones. Neurosci. Biobehav. Rev 27: 119-27.

Matteri, R.L.; Moberg, G.E. and Watson, J.G. (1986): Adrenocorticotropin-induced changes in ovine gonadotropin secretion in vitro. Endocrinology 118, 2091-2096.

McIntosh, T.K.; Vallano, M.L. and Barfield, R.J. (1980): Eeffects of morphine. Pharmacol. Biochem. Behav. 13, 435-441.

Moret, B. (1980): Comportement d'oestrus chez la lapin.Cuniculture 33, 159-161.

Myers, K. and Pool, W.E. (1962): Oestrous behaviour cycles in the rabbit, Oryctolagus cuniculus. Nature, Lond. 195, 358-359.

Mykytowycz, R. (1968): Territorial marking by rabbits. Scient. Am. 218, 116-126.

Nelson, R.J. (1995): An Introduction to Behavioral Endocrinology. Singer Associates Inc. Sunderland, Massachusetts, USA.

Norman, R.L. (1994): Corticotropin-releasing hormone effects on luteinizing hormone and Cortisol secretion in intact female rhesus macaques. Biology of Reproduction 50, 949-955.

Phogat, J.B.; Smith, R.F. and Dobsonm, F. (1997): The influence of stress on neuroendocrine control of the hypothalamic-pituitaryovarian axis. Vet. Bull. 67: vol.415: $551-567$.

Rivier, C. and Rivest, S. (1991): Effect of stress on the activity of the hypothalamo-pituitary-gonadal axis: peripheral and central mechanisms. Biology of Reproduction 45, 523-532. 
Selye, $H$. (1939): The effect of adaptation to various damaging agents on the female sex organs in the rat. Endocrinology 25, 615-624.

Southern, H.N. (1947): Sexual and aggressive behaviour in the wild rabbit. Behaviour 48, 173-193.

Stoebel, D.P. and Moberg, G.P. (1979): Effect of ACTH and Cortisol on estrous behaviour and the luteinizing hormone surge in the cow. Federal Proceedings 38.1254.

Stoufflet, I. and Caillol, M. (1988): Relation between circulating sex steroid concentrations and sexual behavior during pregnancy and post partum in the domestic rabbit. J. Reprod. Fert 82: 209-218.

Suckow, M.A. and Douglas, F.A. (1997): The laboratory rabbit. CRS Press, Boca Raton, New York.

Velazquez-Moctezuma, J.; Salazar, E.D. and Rueda, M.L.C. (1993): The effect of prenatal stress on adult sexual behavior in rats depends on the nature of the stressor. Physiol. Behav. 53: 443- 8.

Ward, O.B.; Ward, I.L.; Denning, J.H.; French, J.A. and Hendricks, S.E. (2002): Postparturitional testosterone surge in male offspring of rats stressed and/or fed ethanol during late pregnancy. Horm. Behav. 41: 229-35.

Worden, A.N. and Leahy, J.S. (1962): The behaviour of rabbits. Cited in: In Behaviour of Domestic Animals pp 397-414. Edit. E.S.E. Hafex. Bailliere, Tindal \& Cox, London.

Yaschine, T.; Mena, F. and Beyer, C. (1967): Gonadal hor-mones and mounting behavior in the female rabbit Am. J. Physiol. 213, 867-872. 